\title{
A luta da terra: Os Sertões
}

\author{
Maria Teresa Vargas
}

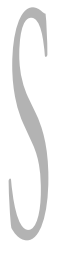

e Dionísio é invocado para dar início a um ciclo renovador do teatro e seus adeptos, $O s$ Sertôes de Euclides da Cunha vem a Jaceguai para celebrar, entre os atuantes, a luta pelo espaço (do solo e da arte) travada pelo Grupo e seu mentor. A idéia não é nova. Está anunciada do programa de $\mathrm{Na}$ selva das cidades encenada em 1969, como anúncio de próxima montagem. Com o pesar do tempo, novos fatos enriquecem o projeto. Repito a pequena anotação de um dos diários: "No dia 7 de janeiro de 1979 é aberta uma janela nos fundos / e se revela um teatro de Dionysios [...]. Começa a ocupação do Oficina com Canudos / Bacantes de um lado, sertanejos de outro". Estabelece-se dessa forma uma tímida aproximação entre a casa-rua, seus rituais e o arraial sertanejo. O próprio José Celso no aspecto e na ação tenta achegar-se a Antonio Maciel, o Conselheiro. Se o proprietário do teatro procura vender o espaço, se existe tão pouca compreensão entre os colegas, críticos, entidades e poderes públicos para com a comunidade em formação, não é difícil ao Oficina/Uzyna identificar-se com o reduto e projetar-se com um refúgio, não só teatral mas de uma cultura em transformação, ocupada por uns poucos, diante dos quais rugem (ou já haviam rugido no passado) um número bastante razoável de soldados. ${ }^{1}$

No entanto, o palco de Jaceguai não é uma cidadela isolada. Caminha com a História. Homens, cidade, país permeiam sua dramatur-

Maria Teresa Vargas é pesquisadora; co-autora de Cem anos do teatro em São Paulo.

1 Em 18 de julho de 1968, o Comando de Caça aos Comunistas (CCC ) atacou o espetáculo Roda Viva, "um acinte, à família e a moral". Vinte e cinco anos depois, o Sr. João Marcos Flaquer, responsável pela 'façanha', recorda o acontecido em reportagem publicada na Folha de São Paulo. Alterando descrições e depoimentos, eis parte do relato: "O CCC estudou por cinco semanas o espaço. 'Precisamos garantir a integridade do público. Os atores receberiam apenas um susto'. O objetivo era realizar uma ação de propaganda e chamar a atenção das autoridades sobre a eminência da luta armada que visava a instauração de uma ditadura marxista no Brasil [...]. Na noite marcada, 110 homens - 70 civis e 40 militares - estavam preparados. Desses, 20 se postaram fora do teatro, 10 na rua dos Ingleses e o restante na rua 13 de maio, para facilitar a fuga. Todos armados com cassetetes, revólveres e metralhadoras [...] Depois de duas horas e meia de um espetáculo que o CCC avaliou como "chato", os 90 homens esperaram o público sair. Cada membro pôs uma luva na mão esquerda, para identificação. O comandante deu ordem para iniciar o quebra-quebra. 5 atiradores ficaram no fundo. 5 destruíram o equipamento do auditório. Outros foram para os camarins agredir o elenco. Cadeiras, extintores, os cenários de Flávio Império, nada resistiu. Flauquer subiu aos camarins, para, segundo ele, evitar abusos. 'Um companhei- 
gia. Seus textos-lições elaborados com cuidado nesses quinze anos têm por obrigação expressar exemplaridades de uma maneira de existir e perceber as coisas que, por sua vez, devem ser compreendidas na mais ampla extensão de seu significado. A meta do texto/espetáculo é rememorar Os sertôes enquanto situação plena de significados. Atraem-se para a cena acontecimentos recentes que possam tornar mais claros os acontecimentos antigos, da mesma forma com que esses venham a iluminar os feitos contemporâneos ('interclarearem-se' seria uma boa palavra), a fim de que em traços vigorosos penetrem em nossa razão e sentidos. A saga do Conselheiro agiganta-se, pois, num painel fantasmagórico, evidenciando através de imagens míticas todos os acontecimentos que vivemos. Antonio, Tamarindo, Bittencourt, Nogueira Cezar não estranham os acompanhantes mais moços: Jânio Quadros, Jango Goulart, Getúlio Vargas com sua carta-testamento.Assemelham-se, ampliam-se. Ajudam reflexōes complexas. Por outro lado Terra e Luta sugerem fatores geradores de uma arte revigorada, apoiada naquilo que faz nosso mistério particular: a imaginação alimentada pelo sonho e pela fantasia. A utilização desses elementos constroem o drama ou seja, ação sem fronteiras impelida por personagens que não bastam a si mesmos, que atraem outros, incorporando-os, acrescentando ao que são parcelas corpóreas ou incorpóreas tornando metáforas o tempo material.

Tudo principia em Os Sertôes com Dionísio em pleno espaço cênico. É ele, naquele momento, uma espécie de mestre-sala descrito na entrada: "(DIONISOS) consulta a bússolarelógio / Olha pro público / Ele está de encontro marcado / Nesse lugar / nessa hora, / Com a multidão presente / pontualíssimo. / A história está acontecendo. / Ele está calmo e ardoroso. / Ele e as Mênadas, durante o prólogo, descobrem realmente o público. / Pra eles é uma emoção."

Dionísio, o senhor dos Teatros é, pois, quem dá início à sessão retirando da terra o tijolo-livro Os Sertôes, colocando-o no sexo de Eduléia, a mesma dos "mistérios" do Mangue. Vigorosa, sofrida, desinibida, "se abre na terra" dando à luz a uma oficina de vida, ou seja, o próprio espetáculo-cerimônia. Terra e Mar (figurinos marrons para Terra em contraste com um enorme tule verde-azulado para o Mar) em "constante conflito secular" vão criando os sertóes/terra, os sertóes/pátria, os sertôes/homens. Juntos traçam o poema do poder popular, esmagado, mas sempre renascido, ainda que através da força do imaginário. Mas o Oficina/ Uzyna tem parte nessa história. Entidades do Teatro procuram a todo custo tecer os fios de ligação. São personagens de mundos ficcionais que já estiveram presentes em espetáculos ou leituras que, embora esgarçadas e fora de seus meios originais, exigem uma interferência na ação ora representada, trazendo para a história que se está narrando dados de sua existência. Abandonadas vagueiam pelos palcos, ansiosas por qualquer chamado. Numa pedra branca, mágica, em plena caatinga, descrevendo a avidez da natureza e dos homens da região, está Nina de $A$ Gaivota, com seu constrangedor monólogo: "Homens, leões, águias e perdizes... I Todas as vidas tendo completado seu triste ciclo... / Se extinguiram... Já há milhares de séculos a terra não carrega / $\mathrm{Na}$ sua superfície criatura viva / E esta pobre lua acende o seu farol".

Seguem-na outros personagens, saltados de outras dramaturgias, outras literaturas: "seu" Olavo, o santeiro de Oswad de Andrade, Olga, Irina e Macha, "as três irmãs", de Tchekhov

ro quis estuprar uma atriz, mas eu impedi'. Flaquer foi o último a sair. Consultou o relógio: a ação havia durado três minutos [...]. 'Atingimos nossa meta. Não houve feridos graves e fizemos o barulho'. [...] 'Foi a ação maior do CCC'. José Celso reconhece: 'O CCC venceu. Uma geração inteira do teatro foi tragada.' (Giron, 1993, ). 
emprestadas, como as três irmãs de Antonio Conselheiro, Lulu, Jack o estripador e Hamlet. O que vem fazer Hamlet em Monte Santo? Descobrir um crime que macula os sertôes? Amarraria a sua dúvida à figura do brasileiro perplexo, sem ação, órfão de pai e rodeado por bajuladores e assassinos? Não caberá a Fortimbras, mas a Hamlet, ansioso pela verdade, dizer as palavras cruciais do livro de Euclides: "Eram quatro apenas: um velho, dous homens feitos e uma criança, na frente dos quais rugiam raivosamente cinco mil soldados." "ELENCO E CONTRA REGRAS VÃO ENCHENDO A PISTA DE CADEIRAS E SE SENTAM PARA CONTEMPLAR O ESPETÁCULO.” É quando mais uma vez intervêm na cena personagens de outras narrativas executando o que manda a rubrica proposta pelo dramaturgo: "SEU OLAVO, O SANTEIRO, COMPRA UM CRISTO COM A CARA DO CONSELHEIRO E OFERECE A EDULÉIA: Te trouxe um santo". Despindo o santo, a prostituta só encontra o sexo. O santo torna-se um falo, símbolo da fecundidade, força da natureza, mas sobretudo estátua de Dionísio, "amálgama” de Dionísio.

Baco e República (que de quando em quando aparecia em cena, sob os mais variados aspectos) voltam à pista. É lacônica em sua mensagem: "Voltei, Voltem" (estamos às vésperas de uma eleição). Mais uma vez cabe às bem pensadas rubricas indicarem o final: "NO IMAGINÁRIO A RECONSTRUÇÃO DO TEATRO... FOGOS DE LUZ NO TRONO VAZIO, NA URNA, NO FALO, NAS MÃOS DE EDULÉIA E EM DIONISOS”.

Os Sertôes nunca foi apresentado na íntegra. Trechos serviram para exercícios e celebraçôes. Uma delas foi em 13 de novembro de 1989, comemorando o centenário da República e a queda recente do "Muro de Berlim" - o que fez José Celso, numa aproximação, trazer durante a cena uma picareta ao ombro, sugerindo a quebra do muro que separa o Oficina do estacionamento do Baú da felicidade, de Sílvio Santos. Mutação de apoteose chamou-se a segunda celebração, nova abertura do teatro, numa tarde de primavera. ${ }^{2} \mathrm{Na}$ realidade foi o encerramento de um curso para formação de atores, utilizando-se da transposição cênica de Os Sertôes.

Nas oficinas Três Rios, apenas com seus corpos, um bastão, panejamentos e uns pouquíssimos elementos, jovens reproduziram o que José Celso chamou de "maquete, uma massa de música, encenação para um espetáculo”. Os vários exercícios modelaram os capítulos do texto: A Terra, O Homem e A Luta. No terceiro capítulo, "tivemos - diz o diretor - que sair da escolinha e cair de novo na vida, para real. Só vamos montar bem a luta, lutando. A luta é entre o teatro de marionetes e o (teatro) do coração."3

Imagens fotográficas bem aranhadas dão uma idéia do excelente resultado dos exercícios que, inspirados pela força do texto, os alunos foram aos poucos arquitetando: "O encontro da Terra com o Mar", "a entrada pelo sertão", “a terra seca", "a gaivota no sertão", "a lua” (representada na cena por um espelhinho redondo colocado harmoniosamente, de encontro à testa da atriz), "o sol" (um enorme leque japonês aberto), "O cavalo morto", "o soldado morto", "o isolamento da terra" (os alunos/intérpretes envoltos em plásticos transparentes). Cantouse e Surubim que tomou parte ativa nos exercícios, fazendo "o Sertanejo", pôde improvisar: "Tudo que fez pela vida / esse brasileiro / Quem lê o livro dos Sertões / ouve falar do Conselheiro / um beato carrancudo / que na guerra de $\mathrm{Ca}-$ nudos / reunia seus irmãos".

Em 23 de setembro de 1989, justamente na segunda abertura do Teatro Oficina, oito alunos

2 A primavera lembra o renascer e é portanto muito cara aos integrantes do Oficina. Foi celebrada em todos esses anos. Marcou-se para 23 de setembro de 1993 a estréia oficial de Hamlet.

3 Palavras de José Celso M. Corrêa em realese enviado aos jornais, datado de 22 de setembro de 1989. 
desse curso da oficina Três Rios, em black-tie, saíram do Teatro, passaram pela porta, na qual o mesmo artista Surubim havia pintado um mandacaru ("as antenas da seca") e receberam nos baixos do Minhocão um tyrso, canudo e bastão. Estavam formados. Era a "mutação de apoteose". Livre dos paramentos da formatura, com os corpos pintados, ao som de chocalhos e tambores voltam ao Teatro recém-aberto, "re- presentam, na dança, seus cavalos, seus animais, totens da terra e do ar, em cordas e trapézios, vôos espaciais e de imaginação, tão necessários nesse terreiro. No pomar (entre a platéia) são plantados coqueiros pros Sertôes e uma parreira pras As Bacantes. Uma rosa para Oswald aguardava uma bananeira que não veio". (Corrêa, 1989)

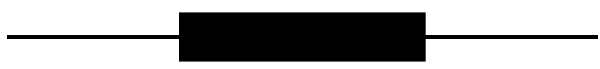

\section{Referências bibliográficas:}

CORRÊA, José Celso Martinez. E o Oficina? mutação de apoteose. Folha de São Paulo, 1 out. 1989, Cad. Ilustrada, p. 3.

GIRON, Luís Antonio. Comando de Caça aos comunistas diz como atacou Roda Viva em 68. Folha de São Paulo, 17 jul. 1993, Cad. Ilustrada, p. 1. 